\title{
Learning from Divided Parties? Legislator Dissent as a Cue for Opinion Formation ${ }^{12}$
}

***Forthcoming in Parliamentary Affairs**

\author{
Eric Merkley \\ Ph.D. Candidate \\ Department of Political Science \\ University of British Columbia
}

Email: eric.merkley@,alumni.ubc.ca

Address: 1866 Main Mall - C425

Vancouver, BC, Canada V6T 1Z1

\footnotetext{
${ }^{1}$ I would like to thank Fred Cutler, Gyung-Ho Jeong, Mark Pickup, Dominik Stecula, and Chris Kam for their very helpful feedback at different stages of this research, and Paul Quirk for allowing the use of the UBC Political Opinion Subject Pool. This research was supported by the Social Sciences and Humanities Research Council of Canada [grant number: 767-2015-2504].

2 The supplementary appendix, data, and replication code will be available on the author's personal website (http:/ /www.ericmerkley.com)
} 


\section{Summary}

Scholars have generally seen united parties as normatively desirable. However, little work has explored the implications of divided parties for public opinion. This paper examines whether legislator dissent reduces public support for the policy positions of divided parties. Dissent can do this two ways: by undermining the consistency of party cues sent to co-partisans of the divided party; or by providing a signal regarding the likely distance of the policy proposal from citizen preferences. These possibilities are evaluated here using a survey experiment. Respondents were exposed to mock news articles about a debate on a bill that manipulated the presence of dissent on government benches and its spatial location - either proximate to the opposition party or on the government party's ideological flank. Legislator dissent appears to reduce the support of government policy for opposition co-partisans, but only when it is centrist and for those with high levels of political knowledge. These results suggest

legislator dissent can act as a cue, if a complex one, to help citizens form policy evaluations in line with their preferences. 
Parliamentary governments are undergirded by strong party discipline. Not only is cross-voting rare, but when it occurs it tends to have little influence on parliamentary outcomes (Franks, 1987). This is generally true across Westminster systems like the United Kingdom and Canada, though with important variation across countries and over time (Cowley, 2002; Kam, 2009). This discipline lies at the core of the responsible party government model of representation, where unified parties stand for coherent policy agendas and submit themselves to judgment by the electorate. Without unity, there is confusion among voters on where parties stand on issues - a serious challenge to this theory of representation. As a result, united parties are often seen as normatively desirable. However, research exploring the possible implications of divided parties on public opinion has been limited.

This paper makes its contribution by exploring whether or not legislator dissent - acting as a cue - reduces support for a policy position on which there is intra-party disagreement. In doing so, it tests for the implications of two theories of why legislator dissent may have this effect. First, legislator dissent may weaken the consistency of party cues. Divided parties have the potential to sow confusion among co-partisans by sending mixed signals on policy. Support for the party's position is then reduced among these citizens compared to what it otherwise would have been. Second, legislator dissent may indirectly signal the proximity of a policy proposal from citizen preferences. Results from a novel experiment are more supportive of the latter theory, suggesting that divided parties can sometimes provide a valuable guide to opinion formation.

\section{Responsible party government and the problem of legislator dissent}

Scholarly conceptualization of the link between the mass public and policy makers is dominated by the responsible party government model. According to this theory of representation, parties - imagined as collectives - articulate citizen demands and enact policy based on these demands (Dalton, 1985). For this model to work, there must be policy divergence between parties that provide citizens with meaningful electoral choices, and parties need to have over time policy consistency so that voters are not confused about what they stand for (Adams, 2001: 4). There is, however, a third condition for the responsible party government model to function. Policy preferences of party officials - at least those that are voiced publicly outside of party caucuses - must be relatively homogenous. Otherwise, voters may be left unsure of how to link their policy preferences to their vote choice.

The key to maintaining this third condition of responsible party government is party discipline. Party leaders in parliamentary systems punish dissenters so their party can function effectively - a necessity that is even more salient for the party in government. Parties in power must survive votes on matters 
of confidence and present a stable government to the electorate. More importantly for our purposes here, party unity facilitates the development of party brands. These brands reduce voter uncertainty over the policies supported by parties and aid in the development of partisan attachments (Cox and McCubbins, 2005; Grynaviski, 2010; Sniderman and Stiglitz, 2012; Proksch and Slapin, 2015). Breakdowns in party discipline can entail costs to parties in public opinion by increasing confusion among voters about their positions on policy.

Research on the implications of legislator dissent for public attitudes towards parties and policies has been uncommon, however. Much of the work to date has focused on the possible benefits of dissent for individual legislators. Experiments conducted in the United States have shown that dissenting representatives tend to make gains among moderate voters, as the nature of their dissent typically leads to bipartisan cooperation (Carson et al., 2010; Harbridge and Malhotra, 2012). Recent work in the British parliamentary context has likewise found legislators are rewarded for dissention with additional media exposure, more support among typically opposing partisans, and the signaling of positive character traits (Vivyan and Wagner, 2012; Campbell et al., 2016).

Research on possible costs of dissent for parties is even scarcer. Scholars have found relatively little evidence that legislator dissent negatively affects parties at the ballot box. It is more likely that the causal arrow runs from party unpopularity to legislator dissent (Kam, 2009). There is also some survey evidence that perceptions of dissent are associated with lower evaluations of party competence in the mass public (Greene and Haber, 2015). This paper will focus on another possibility - that legislator dissent reduces public support for a party's policy position on which there is disagreement.

\section{Cue-taking and policy evaluations}

\subsection{Legislator dissent as a weakening of party cues}

A finding that legislator dissent reduces support for party policy positions would leave open questions about why it does so. The hypotheses advanced here will adjudicate between two possible pathways that legislator dissent could influence policy evaluations. One theory is anchored in a rich literature that examines how citizens make decisions in a low information context governed by rational ignorance (Downs, 1957). Scholars have shown that voters use a number of low cost cues or heuristics in their environment in order to guide opinion formation and vote choice rather than becoming fully informed (Conover and Feldman, 1989; Popkin, 1991; Mondak, 1993; Cohen, 2003; Kam, 2005; Berinsky, 2009). 
The heuristic that has drawn the most attention are party elite cues. They have been shown in experimental settings to be extraordinarily powerful in guiding opinion formation, particularly on novel issues where there is little pre-existing partisan and ideological crystallization (Cohen 2003; Kam 2005). Observationally, elite cues from parties have been found to drive the dynamics in aggregate public opinion on a wide range of issues (Zaller, 1992; Berinsky, 2009).

The effectiveness of party cues, however, is conditional on the consistency of the message. A divided party sends mixed signals to its supporters, weakens the party's brand, and introduces confusion about what the party stands for (Grynaviski, 2010). Legislator dissent may undermine support for party policy positions by weakening the consistency of the party cues sent to the electorate. This will be referred to as the party cuing theory of legislator dissent. One clear observational implication of this theory is that legislator dissent within a party will lower support for the policy position of that party primarily among its co-partisans in the public. These voters are likely to be confused by the signal being sent by their own party's elites, while opposing partisans can rely on their own party's united front to form their own evaluations.

This perspective finds support in Kam's (2009) finding that perceptions of Labour party disunity on the Iraq War primarily influenced the support of Labour partisans for the war. However, this study, and others that examine the link between public opinion and legislator dissent, are ill-equipped to deal with endogeneity. For instance, it is possible that a subset of Labour voters were ideologically predisposed against the Iraq War - particularly among the highly educated with their stronger ideological priors. These voters used their own dissention from the party line to form their broader impressions of disunity in the Labour Party. This process would manufacture a correlation between perceptions of dissent and policy evaluations that is not the result of a causal relationship between the behaviour of party elites and policy evaluations. In contrast, an experimental approach to this question, as done in this paper, features a strong design for causal inference by taking advantage of the random assignment of respondents to treatment conditions that vary the existence of legislator dissent.

H1: Legislator dissent reduces support for the policy position of the divided party among its co-partisans in the public.

\subsection{Legislator dissent as policy proximity signaling}

There is a second major mechanism that can explain why legislator dissent reduces support for party policy positions. It can signal information about the distance of the proposal from citizen preferences. All else being equal, citizens are more supportive of policies proximate to their 
preferences, which can be informed by their identities, ideologies, and values. As per responsible party government, citizens have expectations about how parties are situated vis-à-vis their preferences, and, in the context of low information, often adopt their party's stance in policy debates. In a simplified situation where a government party seeks to move policy toward a closer alignment with its platform and principles, we expect the main opposition party, at a minimum, to defend the status quo from the proposed policy change. Government and opposition co-partisans structure their policy evaluations accordingly.

Parties seek to maintain their brand all else being equal (Proksch and Slapin, 2015). This requires consistency between policy positions and the ideological and social group goals of the party (Adams, 2001). As noted above, citizens have expectations that policy positions occupy a space that reflects this consistency, but there is some uncertainty involved - it is not always clear the degree to which this is true, and, by extension, how far a given policy proposal deviates from the status quo.

A meaningful brand also requires unity among officials that stand for the party in front of the electorate. This brand is valuable for legislators and party leaders alike, as it is important for their joint electoral prospects, while the former is likely to face costly discipline by the latter if the party brand is compromised by dissent. Legislators prefer to tow the party line all things being equal (Kam, 2009; Bendetto and Hix, 2010; Proksch and Slapin, 2015). Thus, citizens know that dissent is an unusual and costly signal.

The occurrence of dissent is a sign of an uncommon situation where a dissenting legislator stands to benefit more from dissention than unity. And, this can happen when the policy position of a party is farther from a legislator's preferences than we might expect given their shared ideological and social group goals. In short, dissent often signals that a party's position occupies an unusual policy space. The implication is that legislator dissent likely does not reduce support for a party's policy position in all cases and for all citizens. Rather, effects are likely conditional on citizen preferences, the spatial proximity of dissenting legislators to these preferences, and whether it is the government or the opposition party that is divided. This theory of legislator dissent's influence on policy evaluations will be referred to as proximity signaling.

Related points have been made in previous work. Citizens often reward spatially proximate legislators and dissenters (Pattie, Fieldhouse, and Johnston, 1994; Canes-Wrone, Brady, and Cogan, 2002; Ansolabehere and Jones, 2010; Vivyan and Wagner, 2012; Campbell et al., 2016). The argument here takes this logic farther. The unusual nature of dissent allows citizens, not just to reward dissenting 
legislators, but to revise their own policy evaluations in light of revealed information on the likely distance of the proposal from their preferences. Dissent acts as a cue to facilitate opinion formation.

The predictions of proximity signaling theory depend on the value of different parameters. However, we can imagine a couple of scenarios to be particularly important when starting with an assumption that there is a government party advancing a policy $(\hat{\mathrm{p}})$ closer to its ideal point and an opposition party opposed to the policy that, by extension, defends the status quo (SQ). In the first scenario the opposition party is divided in its opposition to a government policy proposal. As a result, some legislators join the government party in support for $\hat{p}$. Dissenters are always centrist in this scenario. Proximity signaling theory would predict opposition partisans to be more supportive of $\hat{\mathrm{p}}$ in light of this dissent, because it suggests that $\hat{p}$ is closer to SQ that they would expect if there was unity among their co-partisan elected officials. Unfortunately, this is the same prediction as party cuing theory, where opposition partisans reduce their support for their party's position due to inconsistent party cues.

A second possible scenario is more fruitful in teasing out the implications of our two theories. In this situation a divided government party advances $\hat{\mathrm{p}}$, which is opposed by a united opposition party defending SQ. Dissent can be centrist - where dissenters side with the opposition in opposing $\hat{\mathrm{p}}-$ and extreme - where they instead oppose $\hat{p}$ because it does not deviate enough from SQ. Here, we expect dissent within the government party to lower the evaluations of $\hat{p}$ of opposition party copartisans when dissent is centrist. These citizens generally prefer SQ to any changes the government party will propose, but are unsure of how far the proposal is away from this position. Centrist dissenters that prefer SQ to $\hat{\mathrm{p}}$ send a costly signal that policy that is more extreme than they might otherwise expect. This would not occur when dissenters are on the ideological flank of the government party.

Proximity signaling theory has no clear prediction for government partisans. A larger than expected deviation from the status quo signaled by centrist dissent may be preferable for government copartisans who are located on the ideological flank of their party, or seen as inferior for centrists located between the government and opposition party. The reverse would hold in the case of extreme dissent. Party cuing theory, however, clearly predicts reduced support for government policy among copartisans in the public regardless of the spatial location of the dissent. H2 will then be formulated along the lines of our second scenario to allow us to better tease out the implications of each of our theories. 
H2: Legislator dissent on government benches reduces support for proposed policy among opposition co-partisans in the public, but only when dissenting legislators are centrist.

\subsection{Political sophistication and information processing}

Our two cue-taking theories of legislator dissent likely have other important implications for how citizens respond to legislator dissent. We might expect people of varying levels of political sophistication to respond to dissent in different ways depending on the theory. Party cuing theory sees unified parties as a valuable signal for co-partisans in the general public to guide opinion formation. There are two mechanisms that explain process. First, the stance of the party can serve as a cognitive shortcut that can substitute for priors on a policy issue (Mondak, 1993). A consistent signal from parties allow people to form opinions about politics generally in line with their interests, while maximizing cognitive efficiency.

Second, affect - the positive and negative feelings citizens have towards people and objects - is a powerful guide for opinion formation (Lodge and Taber, 2014). The positive affect people have towards their own parties often leads them to reflexively accept their messages without cognitively demanding push-back. Both of these mechanisms are examples of the peripheral or heuristic processing of information, which is unconscious, automatic, and low effort (Chaiken, 1980). This type of processing is also most relevant for those who are in the greatest need of cognitive efficiency citizens who lack political sophistication (Sniderman et al., 1991; Mondak, 1993; Kam 2005). In short, we expect citizens to be more responsive to party cues if they lack political knowledge and sophistication. The weakening of such party cues due to legislator dissent should influence these citizens the most.

Note that this does not necessarily hold in an observational setting. The reception axiom in John Zaller's Reception-Acceptance-Sampling model tells us that a person's level of cognitive engagement with an issue determines the degree to which they are exposed to and comprehend political messages. Knowledgeable citizens are more likely to respond to elite cues because they are the most likely to be exposed to these signals in their information environment (Zaller, 1992; Berinsky, 2009). In this case, politically sophisticated citizens are simply more likely to learn about legislator dissent. This likely explains why Kam (2009) found the effect of perceived disunity to be stronger among attentive Labour partisans. The prediction, however, is different at the experimental level where everyone is exposed to a given treatment. 
H3A: Legislator dissent reduces support for the divided party's policy position among those with lower political knowledge.

The prediction for proximity signaling theory, however, is quite different. We might expect stronger effects of dissent for highly knowledgeable citizens even at the experimental level. Using cues to form policy evaluations is not always a low cost activity. Political sophistication indicates that individuals have complex cognitive structures that allow for more differentiated and integrated reasoning (Sniderman et al., 1991). Sophisticated citizens are thus more likely to use abstract cues like ideology or interest group endorsements (Sniderman et al., 1991; Lau and Redlawsk 2001). A spatial proximity cue is complicated to use effectively. Citizens would need to understand why dissent is uncommon. They would have to be able to understand the implications of the position of the dissenting legislator for the distance of the policy proposal from their own preferences, and revise their attitudes towards the proposed policy accordingly. This is a complex task likely only manageable for those with a greater understanding of politics.

H3B: Legislator dissent reduces support for the divided party's policy position among those with higher political knowledge.

\section{Data and methods}

\subsection{Context and data}

The experimental manipulation in this study involves the exposure of student respondents to carefully designed mock news articles about the proposal and passage of an education policy in the Canadian province of British Columbia (B.C.). B.C. has different party system than Canada at the federal level. It is polarized with two major parties: the center-right Liberal Party, which formed a majority government under the leadership of Premier Christy Clark at the time of these experiments, and the official opposition party, the center-left New Democratic Party (NDP) under the direction of John Horgan. The B.C. Green party also competes in most districts, but only held one seat in the B.C. legislature during this parliamentary session, while the B.C. Conservative Party is a minor player that had no representation in the legislature. Most ideological conservatives in B.C. vote for the Liberals.

The study was conducted with an online survey experiment using 788 undergraduate political science student subjects who participated in the semi-annual subject pool for the University of British Columbia's Political Opinion Laboratory in December 2015, April 2016, and April 2017 in exchange for course credit. Subjects were required to be Canadian citizens. As with any laboratory experiment 
on student subjects, there are ultimately questions of generalizability. However, there are plenty of grounds to be optimistic about student samples (Druckman and Kam, 2011) and the students subjects used here are broadly similar to a sample of Canadians in a number of respects. ${ }^{3}$ More importantly, there is little reason to suspect that the causal theories outlined in this paper would differ greatly in a sample of the general public. ${ }^{4}$

\subsection{Design and procedure}

Respondents were given a pre-treatment questionnaire that included the moderator variables of interest, and were then exposed to three mock newspapers articles that described a fictional debate over education policy that they were led to believe was recently in the news. The last two of these articles varied depending on their random assignment into one of two conditions:

1. United: policy debate features a united government caucus. Disagreement with proposal is confined to teachers' unions and the opposition B.C. New Democratic Party (NDP).

2. Divided: policy debate features dissent on the education policy from three government backbenchers in addition to the teachers' unions and the opposition B.C. NDP. ${ }^{5}$

${ }^{3}$ Student subjects are very similar to CES respondents in their voting behavior. Table S1 in the supplementary materials shows logistic regression odds ratios for a model that estimated the impact of partisanship, ideology, religiosity and gender on federal Liberal vote choice for both samples. The variance explained by these factors common across both data sets is very similar, and the relative effects of each factor are also nearly equivalent.

${ }^{4}$ Figure S1 in the supplementary materials provides a comparison between 2015 Canadian Election respondents who claimed Canadian citizenship and the subject pool respondents used in this paper. Overall, the student sample is broadly more center-left, and more likely to be federal Liberal partisans. However, student subjects were divided in their loyalties to the two main parties in B.C. much like CES respondents. Student subjects used here are more politically knowledgeable, but somewhat less partisan in their federal party attachments. Findings shown below suggest stronger treatment effects among partisans and those that are high in political knowledge, so it is not obvious which way the results will cut in the broader population.

${ }^{5}$ The treatment with dissent were further subdivided into conditions with a leadership frame in the coverage and without for a different research question. The use of a leadership frame had no additional influence on policy evaluations as shown in Table S3 of the supplementary materials. These conditions are therefore collapsed for the purposes of this paper. 
The policy debate in the treatment condition thus mirrors the second scenario from section 2.2 where a divided government proposes a policy that is opposed by a united opposition party. This allows us to have different predictions for both party cuing and proximity signaling theory.

Subjects first received a primer on independent schools policy in B.C. and an article where Premier Clark, the government party leader, introduced a school vouchers initiative. The primer and first article did not vary across treatment conditions. Next, subjects received one article that covered debate and discussion about the legislative proposal and a second article that reported its passage in the B.C. legislature. These two articles varied across conditions. The goal was for subjects to receive enough information on the issue to form a policy evaluation on a novel issue, while providing enough distracting material unrelated to the manipulation to ensure the treatment was not excessively blunt to call into question its external validity.

A number of choices had to be made in the design of the treatments. First, the scale and scope of dissent may condition how citizens perceive legislator dissent. A small group of three government backbench Members of the Legislative Assembly (MLAs) was chosen to break party ranks. The aim was to find a middle ground between a lone maverick MLA casting a predictable vote against his or her party and a full-scale caucus revolt. Second, a suitable policy had to be chosen. The use of a budget bill was perhaps the most logical choice, but it was rejected to rule out any special effect of dissent on matters of confidence that could potentially bring down the government. The kindergarten-grade 12 education policy field was selected because it likely has greater importance for student respondents without being so applicable to their current lives that the nature of the experimental deception would be recognized. A finding of an effect of dissent on policy evaluations almost certainly generalizes to more important bills, such as those that involve matters of confidence.

An important feature of the experiment worth noting is its emphasis on realism. Mock newspaper articles were specifically designed so that they appear to be from a wide variety of news sources. Respondents were given the choice of which source they wished to receive their information about the policy initiative. ${ }^{6}$ An example article is shown in Figure S2 of the supplementary material. The aim

\footnotetext{
${ }^{6}$ Options included newspapers like the Globe and Mail, National Post, the Vancouver Sun, as well as CBC News and Yahoo News Canada. 66 percent of respondents selected the Globe and Mail and CBC News.
} 
was to ensure that respondents trusted the information they were receiving, while simultaneously believing that the issue was real and important. ${ }^{7}$

Table 1 Experimental Conditions

\begin{tabular}{|l|c|c|c|}
\hline \hline & Wave 1 & Wave 2 & Wave 3 \\
\hline Date & December 2015 & April 2016 & April 2017 \\
\hline N & 187 & 309 & 292 \\
\hline \multirow{2}{*}{ Treatment } & 121 & 224 & 185 \\
\hline \multirow{2}{*}{ Control } & 66 & 85 & 107 \\
\hline \multirow{2}{*}{ Conditions } & \multicolumn{2}{|c|}{ United (Control) } \\
\cline { 2 - 4 } & \multicolumn{2}{|c|}{ Divided (Centrist dissent) } & Divided (Extreme dissent) \\
\hline
\end{tabular}

The first two waves of the survey had dissenting government legislators who agreed with opposition criticism of the legislative proposal. Legislator dissent was thus centrist and proximate to the opposition party. The third wave featured dissenters who believed the government proposal did not go far enough. They were located on the right flank of the governing party. This extreme form of dissent was not ideologically proximate to opposing partisans. All other aspects of the design were identical. The text of the articles and the highlighted changes across conditions can be found in Figures S3-S6 in the supplementary materials. The particulars of the sample and design are shown in Table 1.

After reading the newspaper articles, respondents were asked to fill out a questionnaire that included the response variable: attitudes toward school vouchers. ${ }^{8}$ Subjects were also asked to recall certain features of the news stories to construct a recall index scaled to run from 0 to $1 .{ }^{9}$ Finally, they were debriefed on the nature of the experimental manipulation.

770 percent of respondents correctly perceived the treatment. 92 percent of subjects provided opinions on the policy proposal when given an opportunity, and only one respondent questioned the validity of the news stories.

${ }^{8}$ Support for the government's hypothetical policy proposal was measured with a scale (1-7) composed of two seven-point strongly agree/strongly disagree questions with the following wording: 1) "The B.C. government should provide more resources to help parents have more choice in education, even if this means they send their children to an independent school."; and 2) "The Government of British Columbia should not institute a voucher program for K-12.” Descriptive statistics can be found in Table S2 in the supplementary materials.

${ }^{9}$ On average, subjects answer $78 \%$ of recall questions correctly. 


\subsection{Models}

This paper presents four primary models estimated with Ordinary Least Squares (OLS) regression. The first model simply regresses our dependent variable of interest - attitudes towards the government policy proposal (policy) - on a dummy for the treatment $(1=$ divided). The second model interacts the treatment dummy with a measure of partisanship as follows in equation one to examine whether the treatment is conditional on partisanship (H1; H2):

$$
\begin{gathered}
\text { policy } \left.=\alpha+\beta_{1} \text { (divided }\right)+\beta_{2}(\text { government pid })+\beta_{3}(\text { divided X government pid })+ \\
\left.\beta_{4} \text { (opposition pid }\right)+\beta_{5}(\text { divided X opposition pid })+\varepsilon
\end{gathered}
$$

We can recover the treatment effect for government partisans by summing $\beta_{1}$ and $\beta_{2}$, and for opposition partisans by summing $\beta_{1}$ and $\beta_{5}$. A significant treatment effect for government partisans the co-partisans of the divided party - would be consistent with H1 and party cuing theory, while a significant treatment effect for opposition partisans - the opposing partisans of the divided party - is consistent with $\mathrm{H} 2$ and proximity signaling theory. Two variants of this model are estimated. The first treats partisanship as a dummy variable where ' 1 ' indicates either a supporter of the government or an opposition party depending on the coefficient. The second interacts the treatment with strength of partisanship measures, taken from the Canadian Election Study. The baselines for both estimations are non-partisans. ${ }^{10}$

The second model uses a dummy variable where ' 1 ' indicates the third wave of the study where dissent is extreme, and interacts it with the treatment variable and partisanship as shown in equation two. This will show us whether the cueing effects of dissent are conditional on the spatial location of the dissent (H2). The interpretation of models with three-way interactions is difficult, so marginal effects plots will be presented:

policy $=\alpha+\beta_{1}($ divided $)+\beta_{2}($ government pid $)+\beta_{3}($ divided $X$ government pid $)+\beta_{4}($ opposition pid $)+$ $\beta_{5}($ divided $\mathrm{X}$ opposition pid $)+\beta_{6}($ extreme $)+\beta_{7}($ divided $\mathrm{X}$ extreme $)+$

$\beta_{8}$ (government pid X extreme) $+\beta_{9}($ divided $X$ government pid X extreme) +

$$
\beta_{10} \text { (opposition pid X extreme) }+\beta_{11}(\text { divided } X \text { opposition pid X extreme })+\varepsilon
$$

\footnotetext{
${ }^{10}$ Non-partisans share the same ideological space as government partisans, scoring 4.48 on the zeroto-ten ideological scale, compared to 4.59 for government partisans and 3.14 for opposition partisans, so there is no clear prediction for these respondents for either theory.
} 
The final model estimates a possible moderating effect of political knowledge on the treatment. ${ }^{11}$ Political knowledge is an observational moderator that is correlated with a number of other factors that also have the potential to moderate the effect of the treatment. We have to be concerned with possible confounders. In addition to interacting the treatment with political knowledge, the model will interact it with a number of other possible confounders like recall, ideological extremity and strength of partisanship, which is shown below in equation three. ${ }^{12}$

policy $=\alpha+\beta_{1}($ divided $)+\beta_{2}($ knowledge $)+\beta_{3}($ divided X knowledge $)+\beta_{4-8}($ controls $)+$

$$
\beta_{9-13}(\text { divided X controls) }+\varepsilon
$$

We expect a negative, significant coefficient on $\beta_{1}$ and a positive significant coefficient on $\beta_{3}$ to provide support for $\mathrm{H} 3 \mathrm{~A}$ and party cuing theory. This would indicate treatment effects among the least politically knowledgeable that diminish as knowledge rises. A non-significant coefficient on $\beta_{1}$ and a significant, negative coefficient on $\beta_{3}$ would provide support for $\mathrm{H} 3 \mathrm{~B}$ and proximity signaling theory, as it would suggest treatment effects that rise as knowledge rises.

\section{Results}

The results from the OLS estimates are presented in Table 2. First, there is some support for the notion that legislator dissent negatively influences policy evaluations (model 1). Subjects in the dissent condition expressed lower support for the government's policy by 0.23 points on a 1 to 7 scale of policy support or 0.16 standard deviations [p 0.05, two-tailed]. Model 2 interacts the treatment with respondent partisan identification. It appears that the treatment primarily influences opposition partisans (H2). Among these subjects, policy support is lower by 0.50 points, or 0.36 standard deviations in the treatment condition compared to the control [ $\mathrm{p}<0.01$, two-tailed]. In contrast, policy support among government partisans is lower by 0.16 points or 0.11 standard deviations in the treatment condition compared to the control, but this difference is not significant [ $\mathrm{p} \sim 0.33$, two-tailed].

\footnotetext{
${ }^{11}$ Political knowledge was measured with a four item battery (scaled 0 to 4) asking respondents to identify the last names of the Mayor of Vancouver, the Prime Minister of the United Kingdom, the Governor General of Canada, and the political party of Jason Kenney, a former minister in the previous Harper government.

${ }^{12}$ More information on how these variables are measured can be found in Table S2 of the supplementary materials.
} 
Table 2 OLS Estimates

\begin{tabular}{|c|c|c|c|c|c|c|c|}
\hline & \multirow{2}{*}{$\begin{array}{c}\text { Baseline } \\
1\end{array}$} & \multirow{2}{*}{$\begin{array}{c}\text { PID } \\
2\end{array}$} & \multirow{2}{*}{$\begin{array}{c}\text { Strength } \\
3\end{array}$} & \multirow{2}{*}{$\begin{array}{c}\text { PID } \\
4\end{array}$} & \multirow{2}{*}{$\begin{array}{c}\text { Strength } \\
5\end{array}$} & \multicolumn{2}{|c|}{$\overline{~ K n o w l e d g e ~}$} \\
\hline & & & & & & 6 & 7 \\
\hline Divided & $\begin{array}{c}-0.23^{* *} \\
(0.12)\end{array}$ & $\begin{array}{c}0.08 \\
(0.25)\end{array}$ & $\begin{array}{c}0.10 \\
(0.19)\end{array}$ & $\begin{array}{c}0.37 \\
(0.32)\end{array}$ & $\begin{array}{c}0.22 \\
(0.24)\end{array}$ & $\begin{array}{c}0.30 \\
(0.23)\end{array}$ & $\begin{array}{c}1.24 \\
(0.78)\end{array}$ \\
\hline Government & & $\begin{array}{c}0.64 * * * \\
(0.24)\end{array}$ & $\begin{array}{c}0.38^{* * *} \\
(0.12)\end{array}$ & $\begin{array}{c}0.99 * * * \\
(0.31)\end{array}$ & $\begin{array}{c}0.50^{* * *} \\
(0.15)\end{array}$ & & \\
\hline Opposition & & $\begin{array}{l}-0.27 \\
(0.24)\end{array}$ & $\begin{array}{c}-0.23^{*} \\
(0.13)\end{array}$ & $\begin{array}{c}0.31 \\
(0.33)\end{array}$ & $\begin{array}{c}0.07 \\
(0.17)\end{array}$ & & \\
\hline Divided $*$ Government & & $\begin{array}{l}-0.25 \\
(0.30)\end{array}$ & $\begin{array}{l}-0.18 \\
(0.15)\end{array}$ & $\begin{array}{l}-0.66^{*} \\
(0.38)\end{array}$ & $\begin{array}{c}-0.30^{*} \\
(0.18)\end{array}$ & & \\
\hline Divided $*$ Opposition & & $\begin{array}{c}-0.58^{*} \\
(0.31)\end{array}$ & $\begin{array}{c}-0.36^{* *} \\
(0.16)\end{array}$ & $\begin{array}{c}-1.15^{* * *} \\
(0.41)\end{array}$ & $\begin{array}{c}-0.63^{* * * *} \\
(0.20)\end{array}$ & & \\
\hline Extreme Dissent & & & & $\begin{array}{l}0.64^{*} \\
(0.39)\end{array}$ & $\begin{array}{c}0.41 \\
(0.31)\end{array}$ & & \\
\hline Divided $*$ Extreme & & & & $\begin{array}{l}-0.66 \\
(0.52)\end{array}$ & $\begin{array}{l}-0.26 \\
(0.40)\end{array}$ & & \\
\hline Government $*$ Extreme & & & & $\begin{array}{c}-0.85^{*} \\
(0.49)\end{array}$ & $\begin{array}{l}-0.34 \\
(0.24)\end{array}$ & & \\
\hline Opposition. * Extreme & & & & $\begin{array}{c}-1.24 * * * \\
(0.49)\end{array}$ & $\begin{array}{c}-0.66^{* * * *} \\
(0.26)\end{array}$ & & \\
\hline Divided * Gov't * Extreme & & & & $\begin{array}{l}1.06^{*} \\
(0.64)\end{array}$ & $\begin{array}{c}0.33 \\
(0.31)\end{array}$ & & \\
\hline Divided $*$ Oppo. $*$ Extreme & & & & $\begin{array}{l}1.22 * \\
(0.64)\end{array}$ & $\begin{array}{l}0.59 * \\
(0.32)\end{array}$ & & \\
\hline Knowledge & & & & & & $\begin{array}{c}0.04 \\
(0.07)\end{array}$ & $\begin{array}{c}0.07 \\
(0.08)\end{array}$ \\
\hline Divided * Knowledge & & & & & & $\begin{array}{c}-0.24 * * * * \\
(0.09)\end{array}$ & $\begin{array}{c}-0.20 * * \\
(0.10)\end{array}$ \\
\hline Recall & & & & & & & $\begin{array}{c}-2.32 * * * \\
(0.74)\end{array}$ \\
\hline Divided $*$ Recall & & & & & & & $\begin{array}{l}-0.63 \\
(0.93)\end{array}$ \\
\hline PID Strength & & & & & & & $\begin{array}{c}0.17 \\
(0.13)\end{array}$ \\
\hline Divided * PID Strength & & & & & & & $\begin{array}{c}-0.34 * * \\
(0.15)\end{array}$ \\
\hline Extremity & & & & & & & $\begin{array}{l}-0.10 \\
(0.09)\end{array}$ \\
\hline Divided $*$ Extremity & & & & & & & $\begin{array}{l}-0.08 \\
(0.11)\end{array}$ \\
\hline Constant & $4.17 * * *$ & $4.00^{* * *}$ & $4.05^{* * *}$ & $3.71 * * *$ & $3.89 * * *$ & $4.07 * * *$ & $5.79 * * *$ \\
\hline $\mathrm{R}^{2}$ & 0.00 & 0.14 & 0.16 & 0.15 & 0.17 & 0.03 & 0.13 \\
\hline $\mathrm{N}$ & 647 & 647 & 647 & 647 & 647 & 647 & 558 \\
\hline
\end{tabular}

Model 3 provides similar results when interacting the treatment with strength of partisanship for government and opposition partisans. For government partisans, the interaction between strength of partisanship and the treatment is non-significant $[\mathrm{p} \sim 0.21]$. In contrast, treatment effects clearly rise with the strength of opposition partisanship. Every point increase on the 0 to 3 strength of partisanship measure is expected to lower support for the government policy by 0.36 points, such that 
strong partisans are expected to lower their support for the government policy by 0.97 points or 0.69 standard deviations [p 0.02, two-tailed]. The marginal effects are presented in the top panels of Figure 1. These results fail to provide evidence that legislator dissent reduces support among government supporters who are co-partisans of the divided party $(\mathrm{H} 1)$, and thus little support for party cuing theory. Instead, there is strong evidence that dissent influences opposing partisans, which is more in line with proximity signaling theory $(\mathrm{H} 2)$.
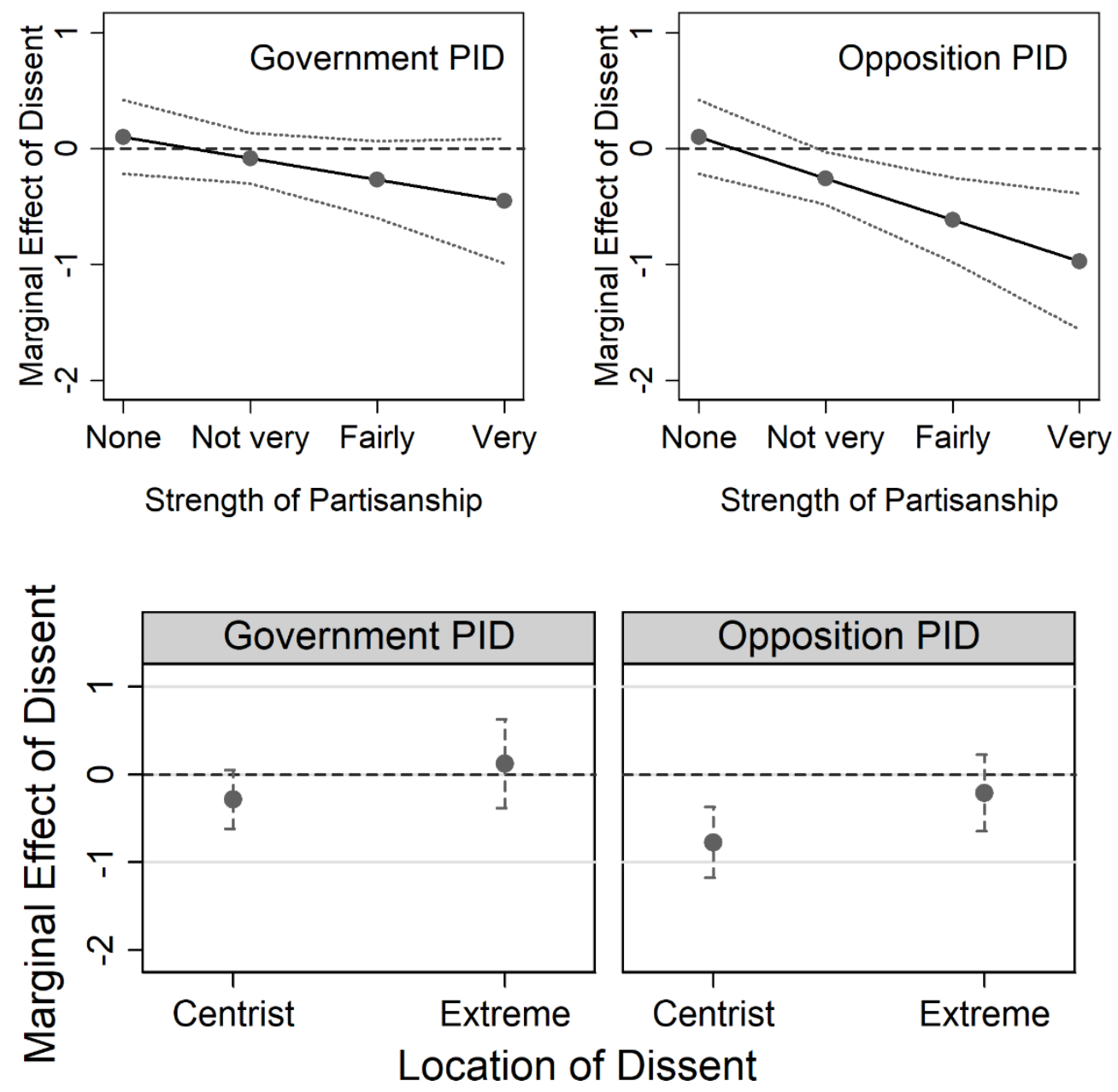

Figure 1 Marginal effect of dissent across strength of partisanship (Top). Marginal effects of centrist and extreme dissent for government partisans and opposition partisans (Bottom). Note: 90 percent confidence intervals.

More evidence in support for proximity signaling theory is found when interacting our treatment, partisanship, and the ideological location of the dissent (model 4). For government partisans, there is no significant treatment effect in either case. In contrast, opposition partisans score 0.77 points lower 
in support for the government policy when exposed to centrist dissent compared to the control condition, or 0.55 standard deviations [ $\mathrm{p} \sim 0.002$, two-tailed]. This treatment effect is reduced to the point of non-significance when dissent is extreme [ $\mathrm{p} \sim 0.42$, two-tailed]. The estimated marginal effects are plotted in the bottom panels of Figure 1.
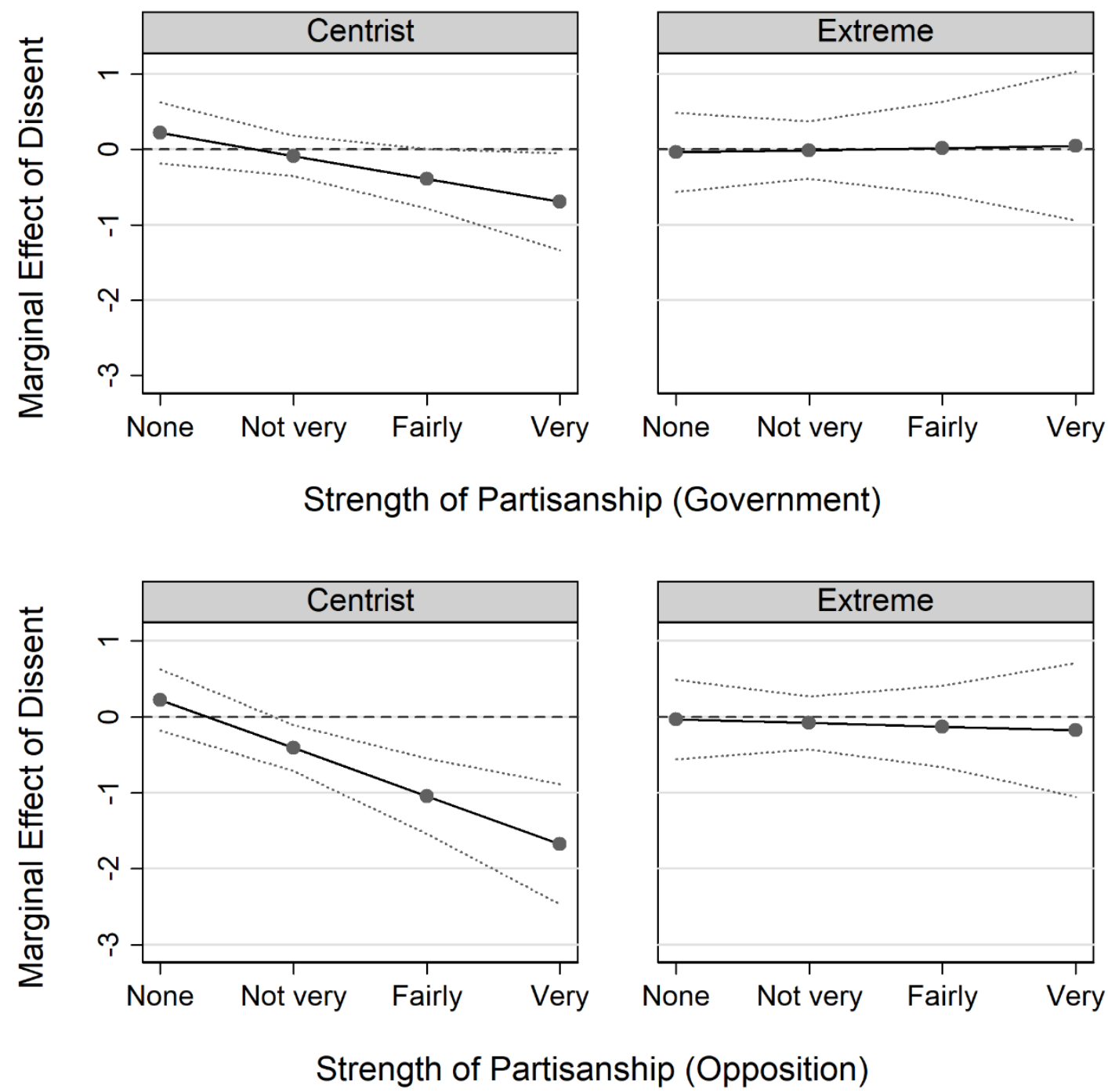

Figure 2 Marginal effect of centrist and extreme dissent across strength of partisanship for government partisans (Top). Marginal effect of centrist and extreme dissent across strength of partisanship for opposition partisans (Bottom). Note: 90 percent confidence intervals.

Evidence is even stronger when incorporating strength of partisanship (model 5). Results are difficult to interpret from the table itself, so estimated marginal effects are plotted in Figure 2. In the top panels, there is some sign of a weak moderating effect of strength of partisanship for government supporters when dissent is centrist - any evidence of this effect vanishes when dissent is ideologically 
extreme. ${ }^{13}$ In contrast, there is a powerful moderating effect of strength of partisanship for opposition partisans, but only when dissent is centrist. Very strong opposition partisans are expected to reduce their support for the government policy by a substantial 1.7 points, or 1.21 standard deviations, with centrist dissent. This pattern disappears entirely when legislator dissent is extreme. All told, there is strong evidence that dissent only reduces support for opposing partisans when it is centrist (H2), which is consistent with proximity signaling theory. ${ }^{14}$

What about political knowledge? The evidence presented thus far suggests legislator dissent serves to signal the ideological location of a policy. This is a comparatively complex heuristic compared to simple party cues. We thus might expect stronger effects of the treatment on those with higher levels of political knowledge (H3B). Results of model 6 suggest this is indeed the case. The interaction term

${ }^{13}$ Caution is in order when interpreting this result since the effect is one half of the size as for opposition partisans and is only marginally significant. However, it may be due to the fact that far more government partisans see themselves as centrist (i.e. spatially located between the opposition and government parties) rather than on the ideological flank of their party (41\% vs. 31\%). On the whole, the finding is more consistent with proximity signaling theory.

${ }^{14}$ For the purposes of this paper I have imagined citizen preferences to be informed by their partisan identities. I did this because the experiment design uses a novel issue that is not firmly anchored in left-right B.C. politics. So, it is not a surprise that partisanship most strongly structures attitudes towards this policy (shown in Table S4 in the supplementary materials). However, citizen preferences can also be structured by other factors, like left-right ideology. Religiosity appears to also matter a great deal on this particular policy, which is not surprising. Most independent schools in B.C. cater to religious groups. We might then expect centrist dissent to matter more for the political left, and for those who are less religious as it would signal policy father away from their preferences than we might otherwise expect. One model was estimated interacting the treatment with left-right ideology (0-10) and religiosity, and another model when interacting those interactions with the spatial location of dissent (Table S5). Left-right ideology does not appear to moderate the effect of the treatment. However, religiosity seems to matter in the predicted way. A different policy area more firmly anchored in left-right politics would have likely made ideology more important relative to partisanship and religiosity. Marginal effects are plotted in Figures S7 and S8. This is likely a result of the issue used in the experiment. 
is significant $[\mathrm{p}<0.01$, two-tailed]. At the highest level of political knowledge we would expect a treatment effect of -0.68 points or 0.48 standard deviations. Political knowledge is an observational variable, so model 4 adds interactions of the treatment with potential confounders like partisan strength, ideological extremity, and item recall. The interactive effect weakens slightly, but is still significant [p 0.04, two-tailed]. The marginal effects are plotted in Figure 3. Treatment effects emerge at the median point of political knowledge in the sample after controlling for other factors. If legislator dissent serves as a cue to guide opinion formation, it is used primarily by those with high levels of political knowledge ( $\mathrm{H} 3 \mathrm{~B}$ rather than $\mathrm{H} 3 \mathrm{~A})$, which is more consistent with proximity signaling theory. ${ }^{15}$

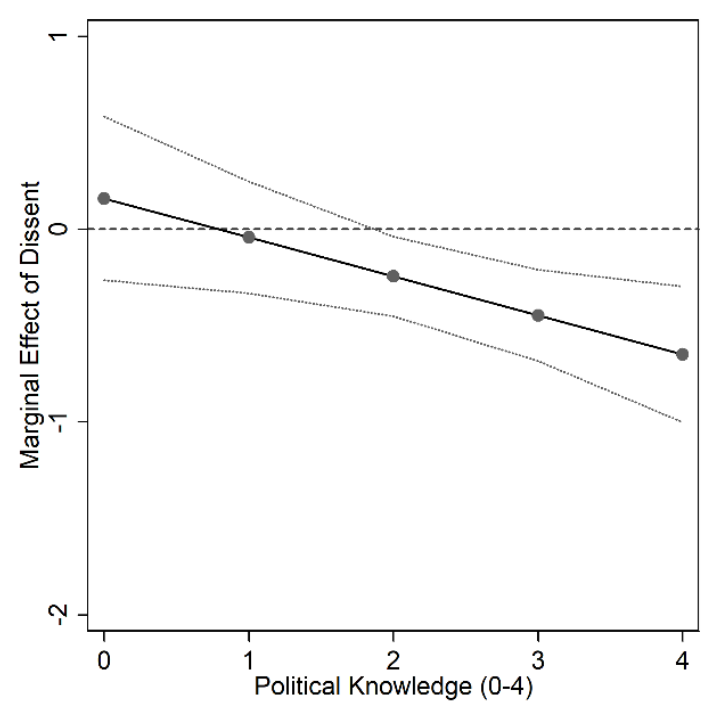

Figure 3 Marginal effect of dissent across levels of political knowledge. Note: 90 percent confidence intervals.

\section{Discussion}

This paper makes two important empirical contributions. First, it provides the first experimental evidence that that legislator dissent undermines support for party policy positions. Subjects exposed

\footnotetext{
${ }^{15}$ It is also likely that treatment effects will be strongest among high knowledge, opposition partisans. This is indeed what we find, as shown in Table S5 in the supplementary materials and in the linear predictions plotted in Figure S9. Sample size limitations, however, prevent the confident estimate of the four-way interactions required to fully test a cross between $\mathrm{H} 2$ and $\mathrm{H} 3 \mathrm{~B}$.
} 
to dissent on government benches were significantly less supportive of the policy than those in the condition where the government was united. This approach has important advantages over more typical observational studies on the link between legislator dissent and public opinion - namely it avoids a serious reverse causality problem where low support for a party or its policy triggers legislator dissent.

The second major contribution of this paper is in its adjudication between two possible theories of how legislator dissent may reduce support for the positions of divided parties - via the weakening of party cues (party cuing theory) or by indirectly signaling the proximity of a policy proposal to citizen preferences (proximity signaling theory). A story consistent with the former in the context of this experimental design would involve findings of lower policy support among co-partisans of the divided party (H1) and stronger effects on those with less political knowledge (H3A). It would be more aligned with the latter if dissent weakened support among opposing partisans when dissent is centrist (H2), and among those with high knowledge (H3B). Results of the experiment presented here show stronger treatment effects among opposition partisans when dissent was centrist. Effects were also stronger among those with high political knowledge. In short, results are far more consistent with proximity signaling theory.

This does not mean legislator dissent always fails to weaken party cues. A stronger dose of dissent may introduce more confusion among co-partisans of the divided party. However, dissent appears to serve as an effective, if complex, cue to help people form opinions in a different way, even at the low levels of dissent tested in this paper. The relative ideological location of dissenting legislators provides information to citizens on the spatial location of a policy proposal. They can then revise their evaluations accordingly. This work joins a growing literature on conditional evaluation accounts of the link between legislator dissent and public opinion (Vivyan and Wagner, 2012; Campbell et al., 2016).

This paper also makes an important methodological contribution to literature on the public opinion implications of legislator dissent with its experimental approach. There is a question of how far we may expect these findings to travel. The dissent featured in these articles is limited in scope, so we can expect the findings to hold where instances of party dissent have greater depth and breadth (Kam, 2009). It is difficult to speculate on whether these findings will generalize cross-nationally. Canada has similar levels of dissent to the United Kingdom, so we may expect similar effects. Crossvoting is rarer in New Zealand and Australia, so we may expect even stronger effects due to its comparative novelty. In more complex multiparty systems it is possible the moderating effect of partisanship will be vary. It is likely that the complexity of these systems will make it harder for citizens 
to learn from divided parties. Ultimately, this design should be implemented in other contexts to put its generalizability to the test.

Similar survey experiments should be used to extend this research for different magnitudes of dissent and to different levels of government and national contexts. The research design does not suffer from endogeneity and can more closely home in on predicted effects on policy and party evaluations rather than using blunt measures of election results or subjective measures of disunity available in off-the-shelf surveys. More generally, findings here suggest that party behaviour can be readily manipulated in an experimental setting. There is no reason to rely solely on respondent perceptions of party behaviour in surveys. Indeed, experiments have been successfully utilized to shed light on the electoral benefits of dissent for individual legislators in the U.S. and the U.K. (Carson $e t$ al., 2010; Harbridge and Malhotra, 2012; Campbell et al. 2016). This trend should continue. Experiments have great potential in expanding our understanding of the relationship between legislative behaviour and public opinion.

This paper offers an amendment to current accounts of legislator dissent and public opinion. Scholars, in the tradition of responsible party government theory, typically view unified parties as essential in facilitating opinion formation and vote choice by providing clear signals about where parties stand on issues to potential supporters. There is a cost to this discipline, however. Dissent can convey important information to voters about particular policies that gets papered over when parties are highly disciplined. This information can also assist citizens in forming evaluations of policy in line with their preferences. Future research on legislator dissent and public opinion should be attuned to both sides of the coin.

\section{References}

Adams, J. (2001) Party Competition and Responsible Party Government: A Theory of Spatial Competition Based Upon Insights from Behavioral Voting Research, Ann Arbor, University of Michigan Press.

Ansolabehere, S., and Jones, P. E. (2010) 'Constituents' Responses to Congressional Roll-Call Voting', American Journal of Political Science, 54, 583-597.

Bendetto, G., and Hix. S. (2007) 'The Rejected, the Ejected, and the Dejected: Explaining Government Rebels in the 2001-2005 British House of Commons', Comparative Political Studies, 40, 755-781.

Berinsky, A. (2009) In Time of War: Understanding American Public Opinion from World War II to Iraq, Chicago, University of Chicago Press. 
Campbell, R., Cowley, P., Vivyan, N., and Wagner, M. (2016) 'Legislator Dissent as a Valence Signal', British Journal of Political Science, 1-24.

Canes-Wrone, B, Brady, D. W., and Cogan, J. F. (2002) 'Out of Step, Out of Office: Electoral Accountability and House Members' Voting', American Political Science Review 96, 127-140.

Carson, J. L., Kober, G., Lebo, M. L., and Young, E. (2010) 'The Electoral Costs of Party Loyalty in Congress', American Journal of Political Science, 54, 598-616.

Chaiken, S. (1980) 'Heuristic Versus Systematic Information Processing and the Use of Source Versus Message Cues in Persuasion', Journal of Personality and Social Psychology, 37, 1387-1397.

Cohen, G. L. (2003) 'Party over Policy: The Dominating Impact of Group Influence on Political Beliefs', Journal of Personality and Social Psychology 85, 808-822.

Conover, P. J., and Feldman, S. (1989) 'Candidate Perception in an Ambiguous World: Campaigns, Cues, and Inference Processes,' American Journal of Political Science, 33, 912-940.

Cowley, P. (2002) Revolts and Rebellions: Parliamentary Voting Under Blair, London, Politicos.

Cox, G. W., and McCubbins, M. (2005) Setting the Agenda: Responsible Party Government in the U.S. House of Representatives, Cambridge, Cambridge University Press.

Dalton, R. J. (1985) 'Political Parties and Political Representation: Party Supporters and Party Elites in Nine Nations', Comparative Political Studies, 18, 267-299.

Downs, A. (1957) An Economic Theory of Democracy, New York, Harper.

Druckman, J. N., and Kam, C. D. (2011) 'Students as Experimental Participants: A Defense of the 'Narrow Data Base”. In Druckman, J. N, Green, D. P., Kuklinski J. H., and Lupia, A. (eds.) Cambridge Handbook of Experimental Political Science, Cambridge, Cambridge University Press.

Franks, C.E.S. (1987) The Parliament of Canada, Toronto, University of Toronto Press.

Greene, Z. D., and Haber, M. (2015) 'The Consequences of Appearing Divided: An Analysis of Party Evaluations and Vote Choice', Electoral Studies, 37, 15-27.

Grynaviski, J. D. (2010) Partisan Bonds: Political Reputations and Legislative Accountability, Chicago, University of Chicago Press.

Harbridge, L., and Malhotra, N. (2011) 'Electoral Incentives and Partisan Conflict in Congress: Evidence from Survey Experiments', American Journal of Political Science, 55, 494-510.

Kam, C. D. (2005) 'Who Toes the Line? Cues, Values, and Individual Differences', Political Behavior, 27, 163-182.

Kam, C. J. (2009) Party Discipline and Parliamentary Politics, Cambridge, Cambridge University Press. 
Lau, R., and Redlawsk, D. (2001) 'Advantages and Disadvantages of Cognitive Heuristics in Political Decision Making', American Journal of Political Science, 45, 951-971.

Lodge, M., and Taber, C. (2014) The Rationalizing Voter, New York, Cambridge University Press.

Mondak, J. J. (1993) 'Public Opinion and Heuristic Processing of Source Cues', Political Behavior, 15, 167-192.

Pattie, C., Fieldhouse, E., and Johnston, R. (1994) 'The Price of Conscience: The Electoral Correlates and Consequences of Free Votes and Rebellions in the British House of Commons, 1987-92', British Journal of Political Science, 24, 359-380.

Popkin, S. (1991) The Reasoning Voter: Communication and Persuasion in Presidential Campaigns, Chicago, University of Chicago Press.

Proksch, S., and Slapin, J. B. (2015) The Politics of Parliamentary Debate: Parties, Rebels, and Representation, Cambridge, Cambridge University Press.

Sniderman, P. M., Brody, R. A., and Tetlock, P. E. (1991) Reasoning and Choice: Explorations in Political Psychology, Cambridge, Cambridge University Press.

Sniderman, P. M., and Stiglitz, E. H. (2012) The Reputational Premium: A Theory of Party Identification and Policy Reasoning, Princeton, Princeton University Press.

Vivyan, N., and Wagner, N. (2012) 'Do Voters Reward Rebellion? The Electoral Accountability of MPs in Britain', European Journal of Political Research, 51, 235-264.

Zaller, J. (1992) The Nature and Origins of Mass Opinion, Cambridge, Cambridge University Press. 